Artigo de Revisão

\title{
UMA REVISÃO ANALÍTICA DA EVAPOTRANSPIRAÇÃO POTENCIAL $^{(1)}$
}

\author{
ÂNGELO PAES DE CAMARGO ${ }^{(2)}$; MARCELO BENTO PAES DE CAMARGO ${ }^{(2,3)}$
}

\section{RESUMO}

Thornthwaite e Wilm introduziram o termo evapotranspiração potencial, em 1944, que representa a perda natural de água do solo vegetado para a atmosfera através da ação conjunta da evaporação e da transpiração. Mais tarde, Penman publicou trabalho semelhante denominando a evapotranspiração de "evaporação natural". Thornthwaite considerou a evapotranspiração potencial (ETp) um elemento meteorológico normal, padrão, representando a precipitação necessária para atender à necessidade de água da cobertura vegetal. A ETp é processo oposto à precipitação, representa a água que retorna forçosamente para a atmosfera, em estado gasoso, e depende da energia solar disponível na superfície do terreno para vaporizá-la. Para estimar a umidade do solo não se deve tomar por base apenas a chuva ocorrida, mas também a ETp, que é a chuva necessária. A primeira é medida facilmente em pluviômetros, porém a ETp necessita ser estimada por meio de fórmulas. Em climas úmidos o modelo de Thornthwaite funciona adequadamente, no entanto em climas muito secos subestima bastante a ETp por não considerar a energia advectiva recebida de áreas secas distantes. O modelo de Penman, que considera em seu termo aerodinâmico essa energia, funciona bem em diferentes condições de umidade climática, necessitando, porém, de numerosos elementos meteorológicos em sua solução, raramente disponíveis na área, o que dificulta seu uso em estudos climáticos e mapeamentos agrometeorológicos. O modelo de Thornthwaite pode ser ajustado para melhor estimar a ETp em condições de clima seco e também de clima superúmido. Esse ajuste baseia-se no emprego de uma temperatura média ajustada em função da amplitude térmica diária.

Palavras-chave: modelo de Thornthwaite, modelo de Camargo-71, balanço hídrico, conceito de ETp, confiabilidade da equação.

\section{ABSTRACT \\ AN ANALYTIC REVISION OF THE POTENTIAL EVAPOTRANSPIRATION}

This work refers to the potential evapotranspiration (ETp) considered as a meteorological element according to Thornthwaite and Wilm. Later on Penman and Sanderson have published also pioneer works on ETp. ETp can be considered the opposite of the rainfall. While this one means the water transferred from atmosphere to the surface, the former means the water back to the atmosphere. ETp represents the transformation of the liquid water state to the gaseous state. This process depends on the energy received from the sun and of the energy balance on a vegetated surface.The soil moisture depends on the water balance between the rainfall and the ETp data. The rainfall data can be easily measured by raingages, but the ETp measurement is more difficult: it is required equations based on several meteorological elements. The Thornthwaite model works well under humid climate conditions, but in dry and arid climates it underestimates the ETp because does not consider the saturation deficit of the air, that is very high in these climatic conditions. Recent studies showed that the problem may be reduced by using a modified mean daily temperature model that uses an adjusted mean temperature

$\left(\begin{array}{l}1 \\ 2\end{array}\right)$ Recebido para publicação em 20 de agosto de 1999 e aceito em 2 de julho de 2000.

$\left({ }^{2}\right)$ Centro de Ecofisiologia e Biofísica, Instituto Agronômico (IAC), Caixa Postal 28, 13001-970 Campinas (SP). Email: mcamargo@cec.iac.br

( $\left.{ }^{3}\right)$ Com bolsa de produtividade em pesquisa do CNPq. 
based on the daily thermometric amplitude (Tmax-Tmin). This amplitude is usually higher in dry climate and lower in superhumid climate, allowing the correction to estimate the ETp values in both cases.

Key words: Thornthwaite model, Camargo-71 model, water balance, concept of ETp, accuracy of equation.

\section{INTRODUÇÃO}

Este boletim não tem a pretensão de fazer uma revisão completa da literatura acerca da evapotranspiração potencial. Tenciona, antes, destacar a literatura relacionada ao conceito desse elemento meteorológico e sua aplicação na agrometeorologia.

O conceito de evapotranspiração potencial, o mais significativo avanço no conhecimento dos aspectos da umidade climática, foi introduzido em 1944 por Thornthwaite, quando trabalhava com problemas de irrigação, no México (MATHER, 1958). A evapotranspiração potencial (ETp) passou a ser considerada, como a chuva, um elemento meteorológico padrão, fundamental, representando a chuva necessária para atender às carências de água da vegetação.

O estudo científico da evaporação natural teve início com Dalton, em 1934 (DeAcon et al, 1958) que demonstrou suas investigações através da fórmula:

$$
E=\left(e_{s}-e_{d}\right) f(u)
$$

em que $\mathrm{E}=$ evaporação por unidade de tempo; $\mathrm{e}_{\mathrm{s}}=$ pressão do vapor em função da temperatura da superfície evaporante; $e_{d}=$ pressão do vapor na atmosfera acima; $\mathrm{f}(\mathrm{u})=$ função da velocidade horizontal do vento (Penman, 1948).

A evapotranspiração potencial (ETp), que representa a chuva necessária, é o processo de perda de água para a atmosfera, através de uma superfície natural gramada, padrão, sem restrição hídrica para atender às necessidades da evaporação do solo e da transpiração.

A evapotranspiração real ( ETr) constitui a perda de água de uma superfície natural, em qualquer condição de umidade e de cobertura vegetal.

A chuva e a ETp são elementos meteorológicos de sentidos opostos, expressos em milímetros pluviométricos. Seus parâmetros, quando cotejados em processo contábil, conhecido como balanço hídrico climático, fornecem dados acerca de deficiências e de excedentes hídricos, essenciais nas pesquisas e trabalhos agrometeorológicos (THORNTHWAITE, 1948).

A ETp é bastante distinta de outro elemento meteorológico, conhecido como evaporação ao ar, obtida pelo evaporímetro de Pichè, que fica instalado dentro de um abrigo meteorológico, o qual indica o poder evaporativo do ar em condições de sombra (Figura 1). Seus dados não são expressos em milímetros plu- viométricos. Não representam as condições naturais da superfície livremente exposta, como a ETp, e não podem ser utilizados no balanço hídrico climatológico. As curvas, na figura 1, da ETp e da evaporação de Pichè são completamente diferentes. O máximo de ETp ocorre no verão, quando há maior quantidade de energia solar para condicionar a evapotranspiração, ao passo que a maior evaporação de Pichè se dá na estação seca, agosto e setembro.

Anteriormente à introdução do conceito da evapotranspiração potencial a climatologia utilizava diferentes unidades de medida para expressar as condições do clima: a chuva indicava a condição hídrica; a temperatura, a condição térmica; e o teor de umidade do solo, sua reserva hídrica. A chuva é expressa em milímetros pluviométricos, a temperatura do ar, em graus térmicos, e a umidade do solo, em porcentagem. Consistem, portanto, três unidades diferentes.

No início da década de 40, Thornthwaite e Holsman (1941), atestaram: "Não existe ainda técnica satisfatória para medir a perda de umidade de superfícies naturais, como de campos e de bacias hidrográficas. Conseqüentemente a falta de dados de evaporação e transpiração tem atrasado bastante a análise e a solução de muitos problemas climáticos e hidrológicos. Espera-se que estudos de evaporação, em superfícies geográficas, dêem informações no sentido de esclarecer e solucionar a questão." Estavam, já, prevendo a solução do problema, com o desenvolvimento e a introdução do conceito de evapotranspiração potencial, bem como dos métodos para quantificá-la. Isso aconteceu, de fato, poucos anos depois, com o trabalho de Thornthwaite e Wilm (1944), apresentado durante o Commitee on evapotranspiration and transpiration, 1943-1944.

Esse fato produziu uma revolução na agrometeorologia. A possibilidade de se usar uma só unidade de medida, milímetros pluviométricos, permitiu contabilizar a disponibilidade de água no solo, através de um simples balanço hídrico climático.

A evapotranspiração potencial corresponde ao processo de transferência da água do solo para a atmosfera, ou a passagem da água do estado líquido para o gasoso. Tal processo requer suprimento de energia, e a única fonte disponível para isso é a radiação solar. A evapotranspiração potencial, portanto, é mais elevada no verão, quando os dias são mais lon- 


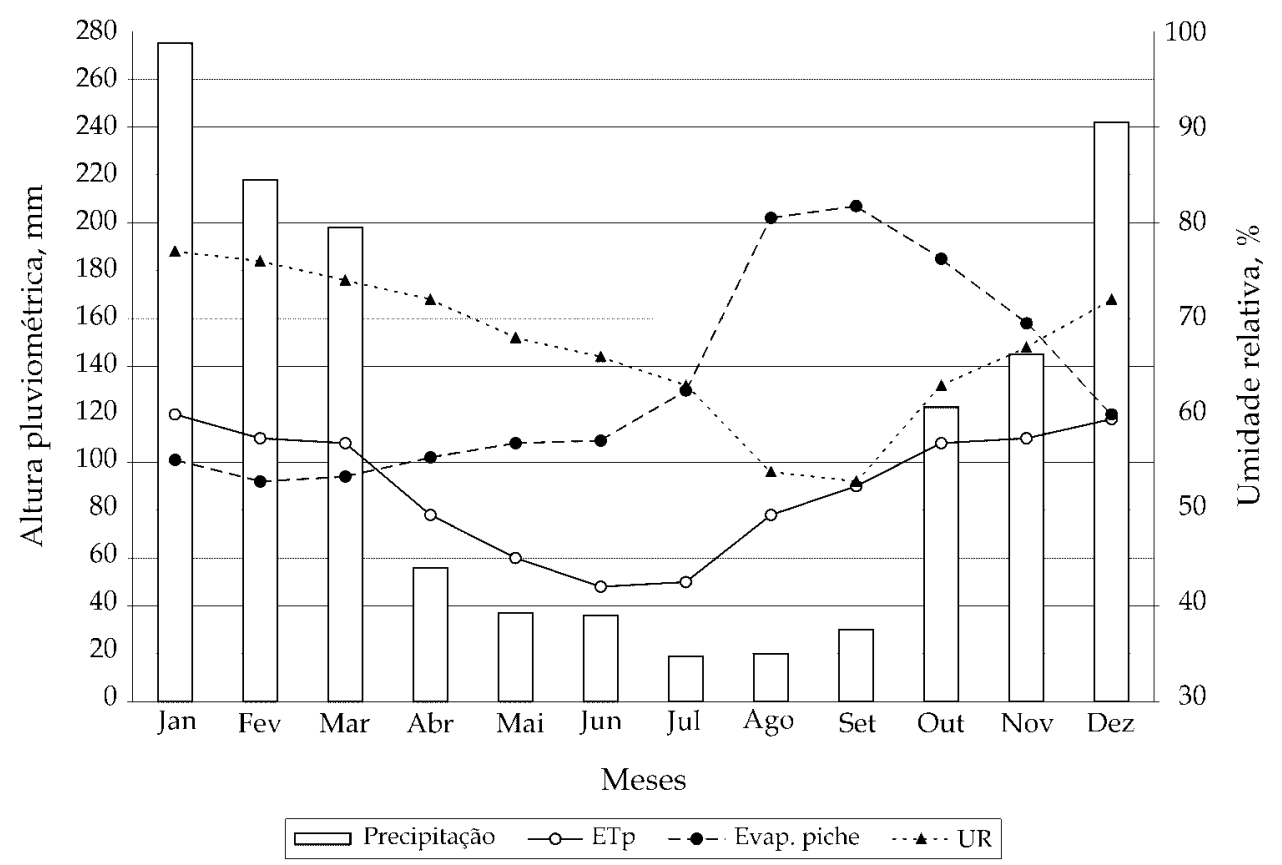

Figura 1. Marcha da ETp, calculada segundo Thornthwaite, da evaporação à sombra, obtida em evaporímetro de Pichè, da umidade relativa do ar e da precipitação pluvial, para a localidade de Ribeirão Preto, SP. Valores mensais médios para o período de 1950 a 1960.

gos e maior a radiação solar. Nos trópicos a energia solar e a evapotranspiração potencial, no curso do ano, são significativamente mais elevadas que em clima temperado.

Quando a umidade no solo é suficiente, a evapotranspiração potencial depende apenas do suprimento de energia solar. Se faltar água no solo a evapotranspiração ficará reduzida, deixando de ser potencial; ocorrerá, então, a evapotranspiração real, menor que a potencial. A evapotranspiração real é um caso especial da evapotranspiração, não se constituindo em um elemento meteorológico.

Thornthwaite e Wilm (1944), ao introduzirem o conceito de evapotranspiração potencial tencionavam chegar a um elemento meteorológico que representasse a necessidade de água da vegetação, em condições similares à da água fornecida pela precipitação pluvial, e quantificar racionalmente o fator umidade, no clima.

THORNTHWAITE (1948) visava aplicar a teoria em trabalhos climatológicos ligados à geografia, à agricultura e à hidrologia e, principalmente, desenvolver uma nova classificação climática, considerada racional, usando como parâmetros hídricos e térmicos os elementos resultantes do balanço hídrico.

Este boletim analisa, inicialmente, a literatura pioneira de Thornthwaite, de Penman e de Marie Sanderson a respeito da evapotranspiração potencial. Em seguida, analisa e interpreta a literatura acerca da evapotranspiração potencial mais ligada à climatologia agrícola.

\section{CONSIDERAÇÕES INICIAIS}

\subsection{Formas de pesquisa}

Filosoficamente, existem duas formas fundamentais de conduzir uma pesquisa (UBALDI, 1965): analítica, mais dedutiva, fundamentada no conhecimento dos fatores causais do fato; e sintética, científica, firmada nos efeitos do fato. A forma analítica caracteriza-se mais pela confiabilidade do que pela precisão das conclusões. Thornthwaite utilizou-a para desenvolver sua equação. A mesma forma de pesquisa foi empregada por Darwin ao desenvolver a tese sobre a seleção natural e a evolução das espécies. A sintética, por basear-se em grande número de dados referentes a seus efeitos, pode chegar a resultados mais precisos. A equação de Penman é exemplo do modelo sintético de pesquisa.

\subsection{Advecção atmosférica}

ROSENBERG et al (1983) referem-se a várias formas de advecção, ou transporte de energia pela atmosfera, as quais influenciam o termo aerodinâmico da equação de Penman. Classifica a advecção em três categorias: global, regional e local.

A advecção global corresponde à circulação geral da atmosfera, função das massas de ar provenientes 
de regiões distantes, que podem ser: polares, equatoriais, continentais, oceânicas, etc.

A advecção regional compreende o recebimento, por convecção, do ar quente e seco da própria região ou mesmo, por advecção, de ar superúmido de áreas aquáticas ou de grandes massas de água da região.

A advecção local corresponde à invasão em áreas irrigadas, por ar seco e quente de áreas secas circundantes. Os vasos dos evapotranspirômetros, por exemplo, necessitam de uma área-tampão circundante, também irrigada, para evitar o efeito da advecção do ar seco, rico de energia latente, o qual iria elevar, aleatoriamente, os valores medidos nos vasos.

\subsection{Confiança na estimativa de uma equação}

Ao correlacionar valores estimados com os observados pela análise de regressão, pode-se considerar os seguintes índices de validade das equações: precisão (r); de concordância ou exatidão (d); e de confiança ou consistência (c).

A precisão, dispersão dos valores em torno da média, é dada pelos coeficientes de correlação (r) ou de determinação $\left(\mathbf{r}^{2}\right)$. São índices estatísticos que indicam o grau de dispersão dos dados obtidos, ou seja, o erro aleatório. Os coeficientes de correlação poderão indicar alta precisão da estimativa, embora tenham possibilidade de apresentar vício de origem, com grande erro sistemático, podendo resultar em informação precisamente errada.

A concordância se refere à exatidão ou à aproximação dos dados estimados aos verdadeiros, observados; pode ser avaliada graficamente pelo afastamento dos pontos cotados no gráfico de regressão em relação à reta de valores iguais, 1:1. Para quantificar matematicamente essa aproximação, foi desenvolvido por Willmott (ROBINSON e HUBBARD, 1990) um coeficiente designado concordância ou exatidão, representado pela letra $d$. Seus valores variam de 0,0 para nenhuma concordância e, 1,0 para concordância perfeita entre eles. O modelo pode ser assim representado:

$$
\mathrm{d}=1-\left[\frac{\sum(\mathrm{Pi}-\mathrm{O} \mathrm{i})^{2}}{\sum(|\mathrm{Pi}-\mathrm{O}|+|\mathrm{O} \mathrm{i}-\mathrm{O}|)^{2}}\right]
$$

em que: $\mathrm{Pi}=$ valores previstos ou estimados; $\mathrm{Oi}=$ valores observados; $\mathrm{O}=$ média dos valores observados.

Neste trabalho é proposto um índice de confiança c, o qual reúne as indicações dos dois coeficientes, $\mathrm{r}$ e d. Corresponde ao seu produto: $\mathbf{c}=\mathbf{r} \times \mathbf{d}$, em que $\mathbf{c}=1$ significa confiança perfeita e $\mathbf{c}=0$, confiança nula.

\section{TRABALHOS PIONEIROS SOBRE ETp}

\subsection{Trabalhos de Thornthwaite e colaboradores}

THORnTHWAITE e WiLM (1944) introduziram os conceitos de evapotranspiração potencial e de evapotranspiração real. Apresentaram uma primeira fórmula para determinação da ETp que envolvia o comprimento do dia, a temperatura média diária e também a umidade relativa do ar. Consideraram, inicialmente, os dados de chuva e o escoamento em bacias hidrográficas de várias partes dos Estados Unidos. Ao refinar a equação, o termo umidade relativa foi suprimido, permanecendo apenas os de temperatura média do ar e de comprimento do dia.

THORNTHWAITE (1946) preparou numerosos balanços hídricos climáticos de diferentes partes do planeta e comparou os excedentes hídricos obtidos com dados de escoamentos de bacias hidrológicas próximas, constatando a eficácia de sua equação. Para melhor avaliar o modelo, THORNTHWAITE (1948) comparou dados de excedentes hídricos estimados pelo balanço hídrico, de doze localidades dos EUA e de um local da República Dominicana, com dados correspondentes ao consumo de água em irrigação. A figura 2A mostra a regressão linear desses dados. Pode-se observar a quase perfeita correlação.

MATHER (1954) comparou dados medidos em uma bateria de evapotranspirômetros instalados em Seabrook, NJ, região de clima úmido durante seis anos seguidos. A análise de correlação dos dados mensais de ETp elaborada para este trabalho, medidos com os dados estimados pelo modelo de Thornthwaite, demonstra a grande confiabilidade dos dados estimados (Figura 2B).

Penman (1956), considerou o modelo de Thornthwaite bastante adequado em condições de clima úmido, apesar de sua inerente simplicidade.

Em geral o modelo de Thornthwaite funciona bem em climas úmidos. Sua resolução mostra-se, porém, trabalhosa. Utiliza um índice "I" complexo, que corresponde ao somatório de doze índices "i" mensais obtidos por equação exponencial.

Para facilitar a resolução de sua equação, THORNTHWAITE (1948) desenvolveu um nomograma especial, posteriormente substituído por tabelas mais práticas (THORNTHWAITE e MATHER, 1957). Hoje, com o uso de computadores, a resolução ficou bastante facilitada.

\subsection{Trabalhos de Penman}

Penman publicou seus primeiros trabalhos com evaporação natural na década de 40 (PENMAN, 1948). Adotou a expressão evaporação potencial, a qual con- 

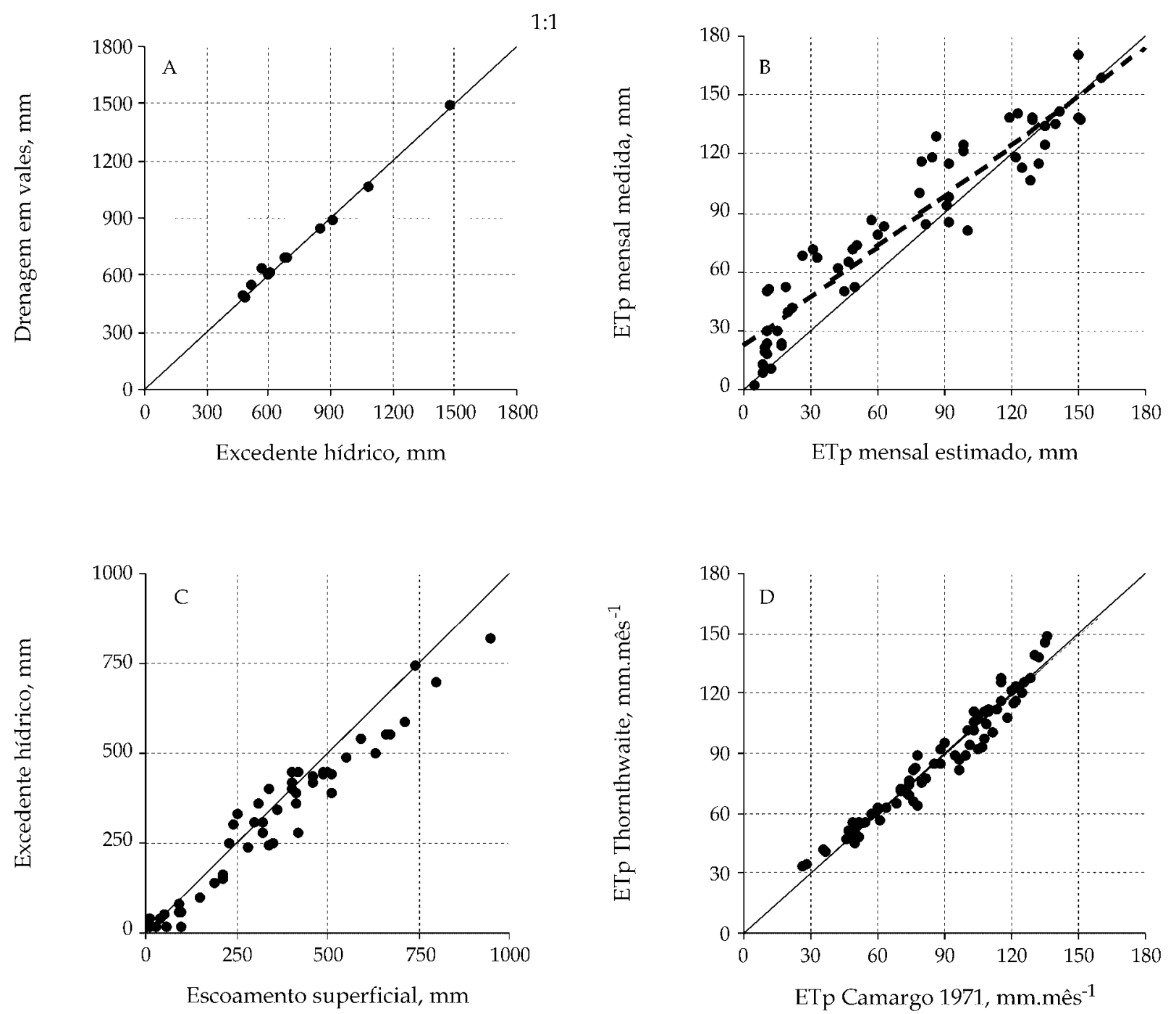

Figura 2. Análise de regressão entre parâmetros diversos e a ETp. A: entre dados anuais de drenagem em vales irrigados dos EUA e da República Dominicana com os correspondentes excedentes hídricos estimados pelo balanço hídrico de Thornthwaite-48. B: entre dados mensais de ETp medidos e estimados segundo Thornthwaite para Seabrook, NJ, EUA. C: entre dados mensais de drenagem em bacias hidrográficas e dados de excedentes hídricos no Canadá. D: entre dados mensais de ETp estimados segundo Camargo-71 e Thornthwaite-48 para 16 localidades do Estado de São Paulo.

siderava mais apropriada que evapotranspiração potencial, no início da década de 50 (PenMAN, 1950, 1952). Utilizou o déficit de saturação do ar (ea-ed), no termo aerodinâmico da equação geral, para estimar a evaporação potencial em superfície natural de água. Para obter a transpiração potencial em superfície gramada propôs um fator de redução, variável de 0,6 a 0,8 no curso do ano e de região para região. PENMAN (1952) propõe também uma adaptação da equação para obter diretamente a transpiração potencial em gramado.

Sem auxílio de computador a equação era de difícil solução. Utilizando-se, porém, nomogramas e tabelas especiais, como as preparadas por VILLA Nova (1967),
FRÈRE (1972) e DoOREnBos e PRUITT (1975), a resolução da equação foi facilitada.

O método Penman é de natureza puramente física, embora tenha aspectos empíricos por utilizar a temperatura do ar em lugar da temperatura da superfície evaporante, como é empregada na clássica equação de Dalton.

\subsection{Trabalhos de Sanderson}

Ainda nas décadas de 40 e 50, a geógrafa Marie Sanderson, de Ontário, Canadá, trouxe valiosa contribuição para avaliar a equação de Thornthwaite, aplicada em regiões frias e até glaciais (SANDERSON, 1948). A autora preparou numerosos balanços hídricos que cobriram basicamente todo o território ca- 
nadense. Os excedentes hídricos obtidos em numerosos balanços foram comparados aos dados correspondentes de escoamentos verificados em bacias hidrográficas. Os resultados mostraram alta correlação entre os excedentes dos balanços e a drenagem das bacias (Figura 2C). O elevado índice de confiança c de 0,95 mostra o bom desempenho da equação de Thornthwaite nas condições de clima frio e úmido do Canadá.

Com os dados de balanços hídricos SANDERSON (1948) preparou cartas de isolinhas anuais da evapotranspiração potencial, das deficiências e dos excedentes hídricos, bem como da classificação climática de Thornthwaite para o Canadá. Essas cartas confirmam plenamente as reais condições climáticas existentes.

Para testar o modelo de Thornthwaite, em condições de latitude extremamente elevada, SANDERSON (1950a; 1950b) instalou, em 1949, dois evapotranspirômetros de percolação, em Norman Wells, no Canadá, à latitude de $64^{\circ} 50^{\prime} \mathrm{N}$. Os valores medidos e estimados de ETp, de julho e agosto, foram basicamente os mesmos: medidos, de $233 \mathrm{~mm}$ e estimados, de $232 \mathrm{~mm}$. Verifica-se que o modelo de Thornthwaite funcionou adequadamente, também em condições de latitude quase glaciais, como no extremo norte do Canadá.

\section{LITERATURA SUBSEQÜENTE SOBRE A ETp}

Burgos e VITAL (1951) elaboraram balanços hídricos, segundo Thornthwaite, para numerosas localidades da Argentina. Com os resultados prepararam cartas de isolinhas anuais para evapotranspiração potencial, excedente e deficiência hídrica. Os autores verificaram que os mapeamentos, com base nos balanços hídricos, ratificaram as condições de umidade reais observadas nas diferentes partes do País.

Harold e Dreibelbis (1951) instalaram, de 1944 a 1949, em Coshoton, Ohio, nos Estados Unidos, região de clima úmido - situada a $360 \mathrm{~m}$ de altitude - uma bateria de três grandes lisímetros de $9 \mathrm{~m}^{2}$ de área e 2,4 $\mathrm{m}$ de profundidade, montados sobre balança com variação de peso medido e registrado automaticamente. O solo dos lisímetros era de estrutura natural e vegetado com grama. Foram obtidos inúmeros dados: evapotranspiração diurna e noturna; condensação, ou orvalhamento; percolação, ou drenagem; escorrimento (enxurrada) e variação no armazenamento. Os tanques eram protegidos por pequena área-tampão e não irrigados. Sendo o clima da região úmido e o solo dos tanques bastante profundo $(2,4 \mathrm{~m})$, os dados de evapotranspiração obtidos podem ser considerados representativos da taxa potencial. THORnthwaite e Mather (1955) os utilizaram no desenvolvimento e na checagem de sua equação.

DeAcon et al. (1958), avaliando a evaporação em evaporímetros, tanques e lagos, bem como a física da evaporação, fizeram excelente análise da literatura acerca desse tema. Demonstraram que a taxa de evaporação decresce com o aumento da superfície, e que a defasagem da evaporação mensal aumenta com o volume e a profundidade da massa líquida. No Lago Superior (EUA), por exemplo, ocorre uma defasagem de seis meses devido ao enorme volume e profundidade da água, muito maior no inverno que no verão. Pela inércia térmica, a água aquecida no verão permanece bem mais quente que a atmosfera no inverno, provocando grande evaporação. O contrário ocorre no verão, época em que a água ainda se encontra fria, e, em contato com o ar quente, pode provocar condensação.

CAMARgo $(1961 ; 1962)$ substituiu no nomograma de Thornthwaite o complexo índice "I" por um índice "T", que corresponde simplesmente à temperatura média anual da região. O novo índice funcionou eficazmente para regiões de clima tropical e equatorial úmidos. Por sua vez, em regiões de clima temperado ou frio, apresentando meses com temperatura média próxima ou abaixo de $0{ }^{\circ} \mathrm{C}$, o autor verificou que o índice " $\mathrm{T}$ " aplica-se com êxito, porém calculado a partir da temperatura média anual apenas dos meses vegetativos, com temperaturas médias positivas. Dessa forma, o índice "T" poderá ser universal e servir para qualquer condição climática. Posteriormente, CAMARGo (1978) preparou uma tabela simples para obter o valor de ETp diário, não corrigido pela latitude, com base no índice "T", o qual facilitou grandemente a estimativa da ETp, segundo Thornthwaite.

CAMARgo (1962) correlacionou dados de ETp estimados por várias equações com dados medidos em baterias de evapotranspirômetros, instalados em três diferentes locais do planalto do Estado de São Paulo. Utilizaram-se evapotranspirômetros de percolação, do tipo Idaban (Mather, 1954). Os tanques, de cimento-amianto, quadrados, de $0,65 \mathrm{~m}$ na lateral e vegetados com grama Batatais (Paspalum notatum Flugge), foram regados pela manhã, a cada dois dias, quando não havia água percolada a recolher.

As condições geográficas e climáticas e os dados anuais de ETp obtidos nas três localidades são apresentadas no quadro 1.

As localidades encontram-se em regiões de clima úmido, com ausência de efeito de advecção regional, permitindo obter nos evapotranspirômetros a ETp confiável, embora com área-tampão relativamente pequena, de cerca de 15 a $20 \mathrm{~m}$ de lado. Os dados 
Quadro 1. Condições geográficas e climáticas e dados anuais de ETp obtidos em três localidades.

\begin{tabular}{lccccr}
\hline Localidades & Latitude sul & Altitude & Temperatura & Chuva & ETp \\
\hline & & $\mathrm{m}$ & ${ }^{\circ} \mathrm{C}(\mathrm{M}+\mathrm{m} / 2)$ & $\mathrm{mm}$ & \\
Campinas & $22^{\circ} 54^{\prime}$ & 670 & 21,6 & 1.280 & 960 \\
Pindamonhangaba & $22^{\circ} 58^{\prime}$ & 570 & 21,2 & 1.300 & 1.150 \\
Ribeirão Preto & $21^{\circ} 11^{\prime}$ & 620 & 22,3 & 1.370 & 1.200 \\
\hline
\end{tabular}

medidos foram correlacionados aos estimados pelos modelos de THORNTHWAITE (1948), de BLANEY e CRIDDLE (1950), de Blaney e Criddle, modificada por CAMARGO (1961; 1962) e de Penman, usando nomogramas de BAVEL (1956).

As análises de correlação com dados medidos mostraram que a equação de Thornthwaite foi a mais satisfatória. A de Blaney e Criddle, original, superestimou os dados de ETp na estação de inverno, como acontece geralmente O modelo de Blaney e Criddle, modificado, funcionou satisfatoriamente. $\mathrm{O}$ método
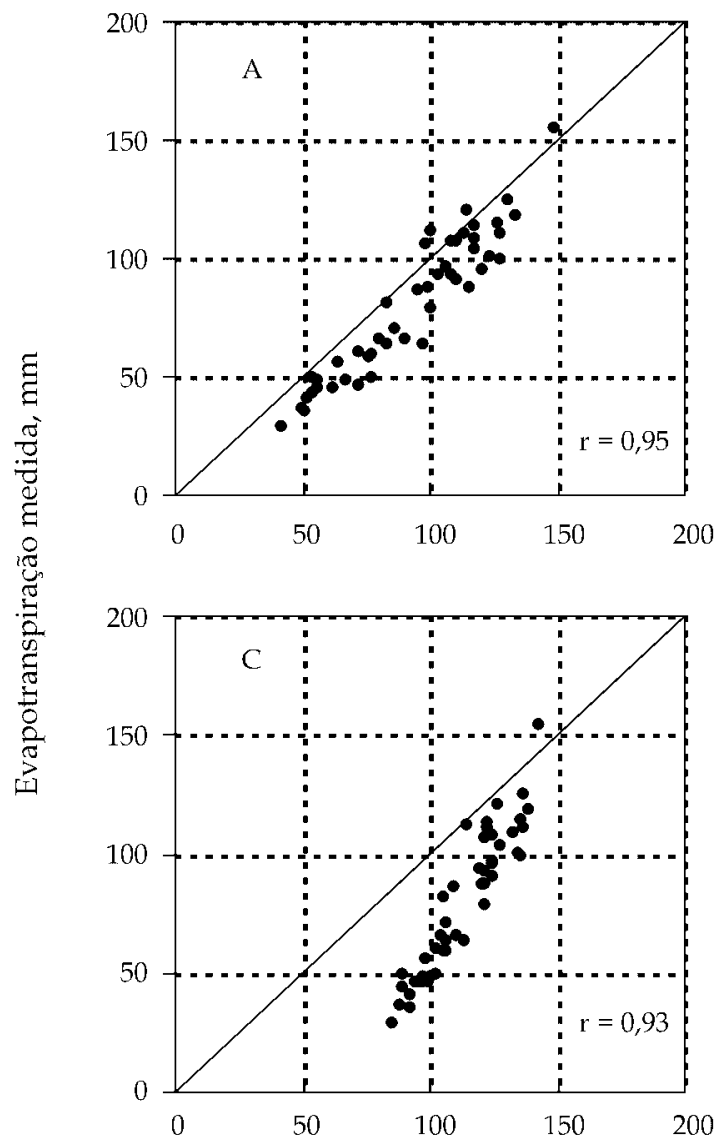

gráfico de Bavel, simplificando o modelo de Penman, subestimou moderadamente os dados no verão e os superestimou no inverno. A figura 3 apresenta as correlações dos dados mensais de ETp, estimados pelas diversos modelos, com os medidos nos evapotranspirômetros. Verifica-se que o modelo de Thornthwaite ofereceu a melhor correlação e consistência, quanto à precisão e à exatidão dos dados.

CAMArgo $(1960,1964,1978)$ preparou balanços hídricos, segundo THORnTHWAIte e MATHER (1955), para o Estado de São Paulo e áreas vizinhas, bem como
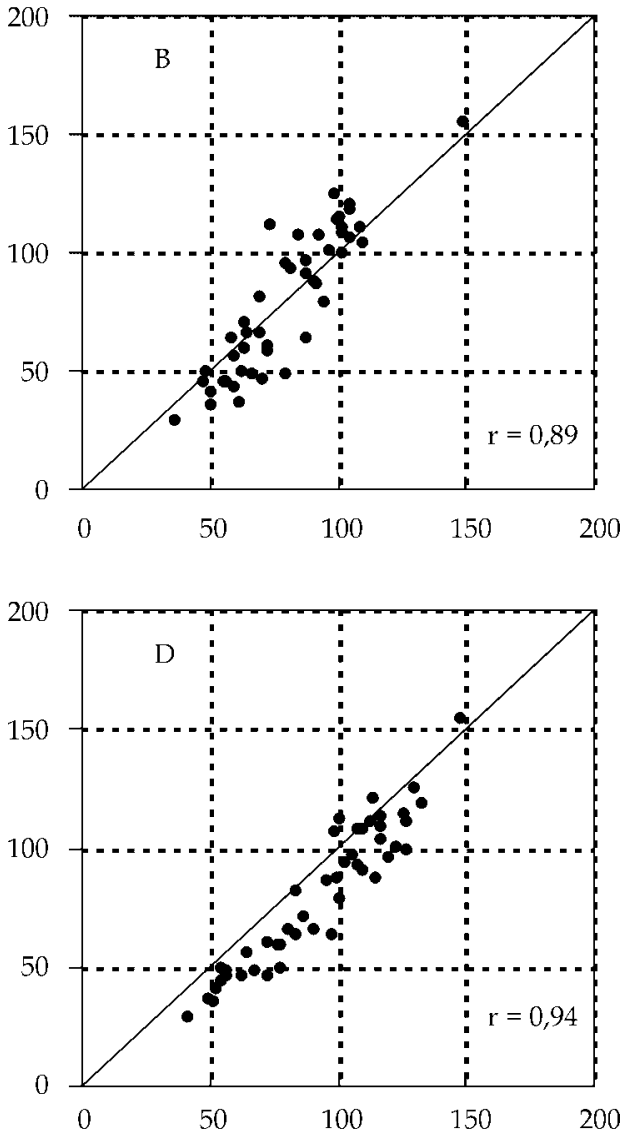

Evapotranspiração estimada, $\mathrm{mm}$

Figura 3. Correlação entre os valores mensais da ETp medidos nos evapotranspirômetros e os estimados pelos métodos de Thornthwaite (A), de Penman com nomograma de Bavel (B), e de Blaney e Criddle original (C) e modificado (D), para Campinas, SP, no período de 1956 a 1959. 
cartas de isolinhas com excedentes e deficiências hídricas. Estas foram publicadas em várias edições do boletim $n^{\circ} 116$ do Instituto Agronômico (IAC). Verifica-se boa concordância das isolinhas desses elementos com as condições hidrológicas e agrícolas efetivamente encontradas no território. A carta de excedentes hídricos, por exemplo, mostra que estes são muito baixos no extremo oeste do Planalto Paulista, onde o lençol freático se apresenta escasso ou muito profundo, com raras nascentes e aguadas, e com água dura ou salobra.

A terceira edição do boletim (CAMARGO, 1971) apresenta, em apêndice, nova equação, extremamente simples, para estimar a evapotranspiração potencial, basicamente com os mesmos resultados da original de Thornthwaite. Foi desenvolvida pelo método analítico baseando-se em resultados da ETp estimados para mais de uma centena de localidades. A equação de Camargo - 71 apresenta-se da seguinte maneira:

$\mathrm{ETp}=$ Qo $. \mathrm{T} . \mathrm{K} \cdot \mathrm{D}$

$\mathrm{ETp}=$ evapotranspiração potencial em mm.dia ${ }^{-1}$.

Qo $=$ radiação solar extraterrestre incidente acima da atmosfera, no dia 15 de cada mês, em mm.dia ${ }^{-1}$ de evaporação equivalente (obtê-la em tabelas especiais).

$\mathrm{T}=$ temperatura média diária do período, em ${ }^{\circ} \mathrm{C}$;

$\mathrm{K}=$ fator de ajuste: 0,01, para Ta (temperatura média anual) até $23,5{ }^{\circ} \mathrm{C} ; 0,0105$ para Ta de 23,6 a $24,5^{\circ} \mathrm{C} ; 0,011$ para Ta de 24,6 a $25,5^{\circ} \mathrm{C} ; 0,0115$ para Ta de 25,6 a $26,5^{\circ} \mathrm{C} ; 0,012$ para Ta de $26,6^{\circ} \mathrm{C}$ a 27,$5 ; 0,013$ para Ta superior a $27,5^{\circ} \mathrm{C}$.

$\mathrm{D}=$ número de dias do período.

CAmargo e CAMARgo (1983) compararam, posteriormente, estimativas de evapotranspiração potencial, em nível mensal e decendial, pela equação de Camargo-71 com a clássica equação de Thornthwaite para 16 localidades paulistas com diferentes condições climáticas (Figura 2D). Notou-se alta precisão $\left(\mathrm{r}^{2}=0,96\right)$, e grande exatidão, pela quase superposição da reta de correlação com a de valores iguais (1:1).

SмITH (1959) estudou, para a condição de clima equatorial úmido na ilha de Trinidad, latitude de $11^{\circ} \mathrm{N}$, as equações de Penman, Blaney e Criddle e de Thornthwaite, verificando, com base em determinações da umidade em solo gramado, que, surpreendentemente, as equações mais complexas, como a de Penman, nem sempre se mostram as mais confiáveis.

PRUITT (1960) utilizou vários tipos de vasos e tanques, elevados e ao nível do solo, nas condições de clima árido de Prosser Wash (EUA), para medir a evaporação. Verificou grande efeito sobre a evaporação da montagem dos tanques a diferentes alturas sobre o solo. O tanque "classe A", por exemplo, mon- tado elevado cerca de $40 \mathrm{~cm}$ de altura evaporou $1.081 \mathrm{~mm}$ em um ano. O mesmo tanque enterrado, com a superfície evaporante ao nível do solo, evaporou apenas $834 \mathrm{~mm}, 23 \%$ a menos. Um tanque mais elevado ainda, a $107 \mathrm{~cm}$ de altura e com diâmetro menor, de $60 \mathrm{~cm}$, evaporou bem mais, $1.196 \mathrm{~mm}$. Outro tanque enterrado, com diâmetro relativamente grande, de $180 \mathrm{~cm}$, evaporou apenas $795 \mathrm{~mm}$, ou $33,5 \%$ a menos. A maior evaporação nos tanques elevados se deve, certamente, à grande exposição de suas paredes à radiação solar e ao vento.

PRUITT (1964) apresenta dados obtidos em Davis, Califórnia (EUA), onde o verão é bastante árido, em lisímetros grandes de 6,1 $\mathrm{m}$ de diâmetro, localizados no centro de extensa área-tampão, de $150 \mathrm{~m} \times 350 \mathrm{~m}$. O trabalho evidenciou a grande subestimativa de ETp pelo modelo de Thornthwaite, em clima árido. Recomenda a correção por um fator entre 1,3 e 2,0, em casos de grande aridez.

Doorenbos e PRUITT (1975) publicaram o conhecido boletim 24 da FAO, com o título "Riego y Drenaje", com assessoramento de pesquisadores de diferentes países, introduzindo o termo evapotranspiração de referência (ETo), a mesma evapotranspiração potencial de Thornthwaite (ETp). Escolheram quatro modelos para estimar a ETp: de Blaney e Criddle, modificada pela FAO; de radiação; de Penman e o tanque "Classe A".

PRUITT e DoOREnbos (1977) estudaram várias formas e métodos de estimar a ETp no verão árido de Davis, California. Compararam dados estimados por diferentes equações aos medidos com a melhor técnica climatológica, em evapotranspirômetros grandes, de 6,1 $\mathrm{m}$ de diâmetro $\left(30 \mathrm{~m}^{2}\right)$, instalados sobre balanças. Foram circundados por extensa área-tampão de 85 a 150 m, em cada lado, e observados durante 5 anos. Apenas a advecção regional, trazendo energia adicional distante influenciou a evapotranspiração potencial medida. Na figura 4 pode-se observar que a equação de Thornthwaite apresentou os dados mais baixos, em virtude de não considerar o efeito da advecção regional. As equações de Penman, Makking, Jensen e Haise, que responderam ao termo aerodinâmico, estimaram bem a evapotranspiração potencial.

STANHILL (1961) trabalhou com evapotranspirômetros de percolação, na região árida de Negev, ao sul de Israel, durante 16 meses. A condição de extrema aridez, sujeita à grande advecção regional, aumentou substancialmente a ETp. Como em Davis, Califórnia. a equação de Thornthwaite subestimou consideravelmente a ETp nessa condição de aridez climática.

MoNTEITH (1965) trata particularmente do aspecto micrometeorológico e físico da evaporação. Analisa o 
$1: 1$
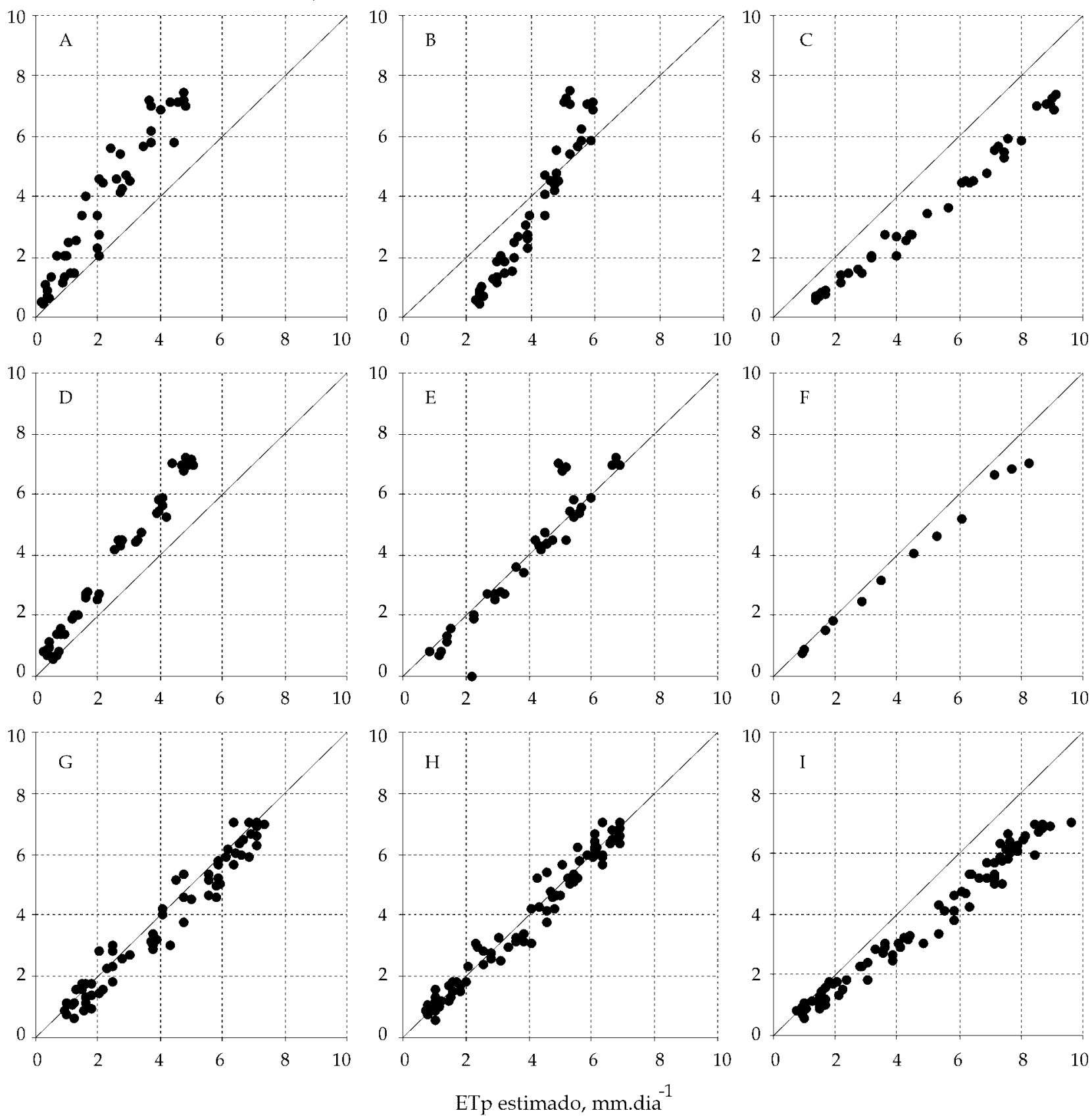

Figura 4. Análise de regressão entre dados medidos em evapotranspirômetros e estimados por vários métodos para as condições de verão de Davis, California, EUA. A: Thornthwaite, subestima no verão árido; B: Blaney e Criddle, superestima no inverno; C: Makking; D: Priestley e Taylor, subestima no verão; E: Penman; F: Jensen e Haise; G: Tanque GGI-3000; H: Tanque USSR 20m2; I: Tanque Classe A, superestima.

parâmetro resistência à evaporação (ra), o qual representa o tempo, em segundos, que leva $1 \mathrm{~cm}^{3}$ de ar para trocar calor (ou vapor d'água) $\operatorname{com} 1 \mathrm{~cm}^{2}$ de superfície evaporante. Essa resistência pode ser externa, fora da folha (ra), ou interna, na própria folha (ri). A externa é condicionada pela diferença entre a pressão do vapor na superfície evaporante $\left(\mathbf{e}_{\mathbf{s s}}\right)$ e a pressão do vapor no ar $\left(\mathbf{e}_{\mathbf{a}}\right)$. É a diferença de potencial que força o fluxo de vapor d'água contra a resistência à difusão externa (ra) e expressa a resistência ao fluxo de vapor para a difusão externa (ra). A resistência interna à transpiração é resultante da resistência encontrada pelas raizes para absorver água em solo com elevada deficiência hídrica. O modelo é capacitado para estimar qualquer forma de evapotranspiração, não se restringindo apenas à potencial. 
MотA et al. (1970), ao prepararem balanços hídricos mensais para o Rio Grande do Sul, usaram a equação de Thornthwaite para estimar a evapotranspiração potencial mensal, não utilizando a de Penman por não contarem com dados suficientes nas poucas estações meteorológicas existentes no Estado.

Oliveira (1971), em tese para Livre Docência apresentada à ESALQ, traz resultados de determinações de evaporação para Piracicaba, de julho de 1968 a junho de 1969. As áreas dos evaporímetros variaram de 1,2 a 19,6 $\mathrm{m}^{2}$, expostos em diferentes alturas sobre o solo. Em Piracicaba, região de clima úmido, os tanques enterrados de forma a ficar a superfície da água ao nível do solo, e protegidos com boa área-tampão, apresentaram ótimos dados de evapotranspiração potencial, muito próximos dos estimados pelas equações de Penman e de Thornthwaite (Quadro 1).

SEdiYAma (1972) fez determinações em evapotranspirômetros-percolação do tipo Thorntwaite, em Viçosa, e comparou os resultados mensais e decendiais de ETp medidos com as estimativas, por diferentes equações. Os tanques dos evapotranspirômetros achavam-se dentro do cercado do posto meteorológico, onde o terreno não é irrigado, ficando, assim, sem a área-tampão irrigada na estação seca. Admitindo estarem os valores medidos um pouco superestimados na estação seca, pela falta de área-tampão, podese considerar o modelo de Thornthwaite com bom desempenho. A equação de Penman superestimou os dados no verão. A de Blaney e Criddle superestimou demasiadamente a ETp no inverno, como era previsto.

HARGREAVEs (1974), em sua primeira equação para estimar a evapotranspiração potencial, utilizou dados de latitude, temperatura média mensal e umidade relativa. Baseou-se em dados de evapotranspirômetros, vegetados com grama, em várias partes do mundo, apresentando a equação:

$$
\mathrm{ETp}=\mathrm{MF} . \mathrm{T} . \mathrm{CH}
$$

em que: MF é um fator mensal com base na latitude; $\mathrm{T}$ é a temperatura média do ar em ${ }^{\circ} \mathrm{F}$; e $\mathrm{CH}$, um coeficiente-função da umidade relativa do ar. Essa equação foi utilizada para calcular a ETp em 156 localidades da Região Nordeste do Brasil (HARGREAVES, 1974).

Posteriormente o mesmo autor (HARGREAVES, 1976, 1977) apresentou nova equação simplificada, na qual foi suprimida a umidade relativa e introduzida a radiação global. Sua fórmula é:

$$
\mathrm{ETp}=0,0075 . \mathrm{RG} \cdot \mathrm{T}
$$

em que: $R G=$ radiação global mensal, em mm.mês ${ }^{-1}$ e $\mathrm{T}=$ Temperatura média do ar em ${ }^{\circ} \mathrm{F}$. Essa equação de Hargreaves- 76 assemelha-se à de Camargo- 71. Esta baseia-se na radiação solar extraterrestre, acima da atmosfera, e a de Hargreaves-76, na radiação global, ao nível do solo.

Villa Nova (1967) apresenta em tese de doutorado, um método prático para resolução da equação de Penman, com base em ábacos e tabelas. O mesmo autor e colaboradores (Villa Nova et al., 1968) trazem exemplos de aplicação de ábacos e tabelas, que vieram facilitar enormemente a resolução da equação. Admitem os autores que o método de Penman foi o mais preciso, sendo, por isso recomendado pela Organização Meteorológica Mundial (OMM). Levando-se em conta, porém, a imensa praticidade do modelo de Thornthwaite, o qual necessita como elemento meteorológico apenas a temperatura média do ar, diversos autores consideram tal método como ideal para estudos climatológicos e em projetos de quantificação de irrigação.

FRĖRE (1972) apresenta também um método bastante prático para resolução da fórmula de Penman, quer para se estimar a evapotranspiração potencial em gramado, quer para a evaporação de superfície de água livre. Requer apenas o preenchimento de formulários e uso de tabelas.

Camargo e Pereira (1981) discutem o conceito de evapotranspiração potencial de THORNTHWAITE (1946). Admitem que qualquer fórmula para estimá-la deve atender a importantes requisitos, tais como: exeqüibilidade, simplicidade e confiabilidade. A equação de Thornthwaite, por atender a tais equisitos, tem sido muito empregada em estudos e trabalhos climatológicos.

WiLLmotт et al. (1985) apresentaram trabalho do ponto de vista geográfico, fundamentado no balanço hídrico segundo Thornthwaite. Baseando-se em balanços mensais para mais de 13.000 estações meteorológicas por todo o globo, prepararam cartas a respeito de armazenamento da umidade do solo, cobertura de neve e evapotranspiração real. Observaram que os dados mensais de ETp estimados mostraram-se freqüentemente mais baixos que os obtidos em lisímetros. No entanto admitem a possibilidade de estarem, estes últimos superestimados. Freqüentemente os gramados dos lisímetros acham-se superexpostos, mais altos e recobrindo o bordo circundante dos vasos. Isso aumenta significativamente, porém de modo incorreto, a evapotranspiração medida.

MALEK (1987) caracteriza o efeito da energia advectiva regional sobre a evapotranspiracão potencial em uma região muito árida, a de Baygah, Shiraz, ao sul do Irã. Acentua que, em região úmida, é a radiação solar a fonte de energia condicionante da ETp. Em regiões áridas, porém, a advecção regional constitui também importante fonte de energia para condicio- 
nar a ETp, transferindo calor sensível e, principalmente, a energia latente da área seca circundante para o campo úmido, irrigado. Quando essa transferência ultrapassa uma faixa superior a $200 \mathrm{~m}$ de largura, pode-se considerar a presença de advecção regional.

Pereira e CAMARgo (1989) fizeram cuidadosa análise da literatura que critica o desempenho da fórmula de Thornthwaite na estimativa da evapotranspiração potencial. Concluíram que, apesar de basear-se apenas em dados de temperatura média e do comprimento do dia, o método tem apresentado bons resultados em regiões de clima úmido. Para condições de estação seca pronunciada ou em climas áridos, a crítica mostra-se pertinente, não considerando a energia recebida por advecção regional do ar seco, rico de energia latente recebida das áreas secas distantes.

STEINER et al (1991) esclarecem que as equações de estimativa da evapotranspiração potencial não têm sido testadas adequadamente em regiões de seca ou aridez. Para testar os modelos nessas condições foram instalados dois lisímetros sobre balança, no Texas (EUA). Os lisímetros foram vegetados com sorgo, cercados por uma área-tampão de 5 ha com a mesma vegetação e bem irrigada. Os modelos avaliados foram: Penman, Penman-Monteith, Jensey-Haise e Priestley-Taylor. A equação de Penman-Monteith apresentou a melhor estimativa de ETp; a de Penman superestimou entre $20 \%$ e $40 \%$; a de Jensey-Haise, que requer apenas dados de temperatura e de radiação solar global, superestimou em cerca de $30 \%$.

SмITH (1991), com a colaboração de autores especializados de numerosos países representantes de organizações como a ICID, ICRISAT, WMO, CSIRO, além da FAO, preparou um extenso trabalho visando atualizar conhecimentos sobre a evapotranspiração. Destaca a contribuição da FAO, pelo seu conhecido Boletim n. 24. Os autores desses trabalhos desconsideraram a valiosa contribuição de Thornthwaite e de Marie Sanderson, que introduziram o conceito de evapotranspiração potencial e publicaram os primeiros trabalhos utilizando esse elemento meteorológico, fundamental no preparo do balanço hídrico e nos estudos agrometeorológicos e geográficos.

Camargo e Picini (1995) procuraram desenvolver uma equação para estimar uma temperatura efetiva (Tef), em função da amplitude térmica diária que pudesse ser utilizada no modelo de Thornthwaite e similares, visando corrigir a estimativa da ETp em condições especiais - de aridez e de superumidade nas quais carecem de exatidão, na medida em que subestimam a evapotranspiração potencial, no primeiro caso, e a superestimam, no segundo.

\section{CONCLUSÕES}

1. O modelo de Thornthwaite funciona adequadamente em regiões de clima úmido, independentemente da latitude e altitude. Apresenta resultados satisfatórios em clima frígido do norte do Canadá, no clima temperado de New Jersey, Estados Unidos; no tropical do Estado de São Paulo; no equatorial da República Dominicana, e na Ilha de Trindade, no Caribe.

2. Em clima úmido, os modelos de Thornthwaite e de Penman normalmente apresentam resultados comparáveis e satisfatórios. Em condições de aridez, o modelo de Thornthwaite subestima com freqüencia a ETp. Em situação de superumidade topoclimática, ao contrário, pode superestimar a ETp.

3. Para corrigir a subestimativa em condições de aridez ou a superestimativa em caso de superumidade pode-se empregar uma temperatura média, corrigida em função da amplitude térmica diária, denominada temperatura efetiva.

4. Em área seca, o tanque "Classe $\mathrm{A}$ " localizado fora da cultura irrigada, sem proteção da faixa-tampão e montado elevado em relação ao solo, superexposto, torna-se sujeito às advecções locais e regionais, apresentando resultados superestimados. Com o tanque enterrado e a superfície da água no mesmo nível da grama externa, os resultados foram melhores, próximos da verdadeira evapotranspiração potencial.

5. O modelo de Blaney e Criddle estima satisfatoriamente a evapotranspiração potencial no verão seco da Califórnia, onde é usada para quantificar a irrigação. No entanto, superestima consideravelmente a evapotranspiração, no inverno. $\mathrm{O}$ mesmo ocorre no sudeste brasileiro, com característica de clima seco, no inverno, resultando superquantificação da irrigação nesse período.

6. O modelo de Thornthwaite foi simplificado sobremaneira com a substituição do complexo índice "I" (soma dos 12 índices " $\mathrm{i}$ " mensais) pelo índice "T", de Camargo, que corresponde apenas à temperatura média da região, sem considerar os dados dos meses frígidos, com temperaturas negativas em graus Celsius.

7. A fórmula de Camargo-71 fornece, basicamente, os mesmos resultados do modelo convencional de Thornthwaite.

8. Penman e Monteith consideram a evapotranspiração potencial como parâmetro físico, micrometeorológico, biológico, entre outros. Thornthwaite trata-a como elemento meteorológico padrão, para emprego na agrometeorologia, agronomia e geografia.

\section{AGRADECIMENTOS}

Os autores agradecem a contribuição dos colegas: 
Dr. Homero Bergamashi, pela revisão do texto e observações que muito valorizaram o trabalho. Dr. Malaquias da Silva Amorim Neto, pela revisão do texto e das referências e sugestões para enriquecer o trabalho. Dr. Sílvio Steinmetz, pela revisão do texto, com observações preciosas para dar maior clareza às informações. Dr. Paulo Henrique Caramori, pela minuciosa revisão do texto e valiosas sugestões. Dr. Luiz Roberto Angelocci, pela revisão do texto e valiosas sugestões. Dr. Antônio Roberto Pereira, pela valiosa crítica ao trabalho. Dr. Paulo César Sentelhas, pela preciosa colaboração nas análises de regressão. Sr. Wander José Pallone Filho, pela ajuda no preparo das figuras.

\section{REFERÊNCIAS BIBLIOGRÁFICAS}

BAVEL, C.H.M. van. A nomogram to estimate maximum evapotranspiration. Charlotte, North Carolina State College, 1956. n.p. (Mimeografado)

BLANEY, H.F.; CRIDDLE, W.O. Determining water requirements in irrigated areas from climatological and irrigation data. Washington, D.C.: Soil Conservation Service, 1950. 48p.

BURGOS, J.J.; VIDAL, A.L. The climates of the Argentina Republica according to the Thornthwaite climatic classification. Buenos Aires: Association of American Geographers, v.XLI, n.3, p.237-263, 1951.

CAMARGO, A. Paes. O balanço hídrico no Estado de São Paulo. Campinas: Instituto Agronômico, 1960. 15p. (Boletim, 116)

CAMARGO, A. Paes. Contribuição para a determinação da evapotranspiração potencial no Estado de São Paulo. Piracicaba,1961, 49p. Tese (Doutorado)-ESALQ/USP.

CAMARGO, A. Paes. Contribuição para a determinação da evapotranspiração potencial no Estado de São Paulo. Bragantia, Campinas, v.21, p.163-203, 1962.

CAMARGO, A. Paes. Balanço hídrico no Estado de São Paulo. 2.ed. Campinas: Instituto Agronômico, 1964. 20p. (Boletim, 116)

CAMARGO, A. Paes. Balanço hídrico no Estado de São Paulo. 3.ed. Campinas: Instituto Agronômico, 1971. 24p. (Boletim, 116)

CAMARGO, A. Paes. Balanço hídrico no Estado de São Paulo. 4.ed. Campinas: Instituto Agronômico, 1978. 28p. (Boletim, 116)

CAMARGO, A. Paes; PEREIRA, A.R. A evapotranspiração potencial segundo Thornthwaite. In: CONGRESSO BRASILEIRO DE AGROMETEOROLOGIA, 2., 1981, Pelotas. Anais... Pelotas: Sociedade Brasileira de Agrometeorologia, 1981. p.110-118.

CAMARGO, A. Paes; CAMARGO, M.B. Paes. Teste de uma equação simples para estimativa da evapotranspira- ção potencial baseada na radiação solar extraterrestre e na temperatura do ar. In: CONGRESSO BRASILEIRO DE AGROMETEOROLOGIA, 3., Campinas, Anais... Campinas: Sociedade Brasileira de Agrometeorologia, 1983. p.229-244.

CAMARGO, A. Paes; PICINI, A.G. Modelo para estimativa de ETp considerando a advecção regional em climas áridos. In: CONGRESSO BRASILEIRO DE AGROMETEOROLOGIA, 9., 1995. Campina Grande, Anais... Campina Grande: Sociedade Brasileira de Agrometeorologia, 1995. p. 407-408.

DEACON, E.L.; PRIESTEY, C.H.B.;SWINBANK, W.C. Evaporation and the water balance. In: ARID ZONE RESEARCH. Climatology: Reviews of research. Paris: UNESCO, 1958. p. 9-34.

DOORENBOS, J.; PRUITT, W.O. Guidelines for predicting cropwater requirements. Rome: Estudio FAO, 1975., 1975. 179p. (Irrigation and Drainage, Paper, 24)

FRÈRE, M. A method for the practical application of the estimation of potential evapotranspiration and evaporation from a free water surface. Rome: FAO, 1972, 21p.

HARGREAVES, G.H. Precipitation dependability and potentials for an agricultural production for Northeast Brazil. Cusushash: EMBRAPA and Utah State University, 1974. 123p.

HARGREAVES, G.H. Climate and irrigation requirements for Brazil. Logan: Utah State University, 1976. p.44.

HARGREAVES, G.H. Water requirements manual for irrigated crops and rainfed agriculture. Logan: Utah State University, 1977. 41p.

HAROLD, L.L.; DREIBELBIS, F.R. Agricultural hydrology as evaluated by monolith lysimeters. Washington, D.C.: Department of Agriculture, 1951. 149 p.

MALEK, E. Comparison of alternative methods for estimating ETp and evaluation of advection in the Bajgah area. Agricultural and Forest Meteorology, Amsterdam, v.39, p.185-192, 1987.

MATHER, J.R. A summary of evapotranspiration at Seabrook, 1947-1953. In: The measurement of potential evapotranspiration. Seabrook: The Johns Hopkins University, 1954. p.7-28 (Publications in Climatology, v. 7, n.1)

MATHER, J.R. Preface. Centerton, N.J., 1958, p. 247-248. (Publications in Climatology, v. XI, n.3)

MONTEITH, J.L. Evaporation and environment: Rothmsted Experimental Station. Harpendem, Herts, v.19, p.205-234, 1965. (Publications in Climatology, v. XI, n.3)

MOTA, F.S.; GOEDERT, C.O.; LOPES, N.F.; GARCEZ, J.R.B.; GOMES, A.S. Balanço hídrico no Rio Grande do Sul. Pesquisa Agropecuária Brasileira, Brasília, v.5, p.127,1970 . 
OLIVEIRA, A.S. Estudos comparativos da evapotranspiração potencial estimada por tanques e pelo método de Penman. Piracicaba: ESALQ / USP, 1971. 113p.

OMETO, J.C. Evapotranspiração potencial. In: Biologia vegetal. São Paulo: Ceres, 1981. p.280-293.

PELTON, W.L.; KING, K.M.; TANNER, C.B. An evaluation of the Thornthwaite and mean temperature methods for determining potential evapotranspiration. Agronomy Journal, Madison, v.52, p.387-395, 1960.

PENMAN, H.L. Natural evaporation from open water, bare soil and grass. Proceeding Royal Society, London, v.193, p.120-143. 1948.

PENMAN, H.l. Evaporation: an introductory survey. Netherlands. Journal of Agricultural Science, Cambridge, v.4, p.9-29, 1956.

PENMAN, H.L. Evaporation over British Isles. Quarterly Journal of the Royal Meteorological Society, Bangkok, v.76, p.372-383, 1950.

PENMAN, H.L. Experiments on irrigation of sugar beet. Journal of Agricultural Science, Cambridge, v.42, p.286292, 1952.

PEREIRA, A.R.; CAMARGO, A. Paes. An analysis of the criticism of the Thornthwaite's equation for estimating potential evapotranspiration. Agricultural and Forest Meteorology, Amsterdam, v.46, p.149-157, 1989.

PRUITT, W.O. Relation of consumptive use of water to climate. Transactions of the ASAE, St. Joseph, v.3, n.1, p.9-13, 1960.

PRUITT, W.O. Cyclic relations between evapotranspiration and radiation Transations of the ASAE, St. Joseph, v.7, n.3, p.271-275, 1964.

PRUITT, W.O.; DOORENBOS, J. Empirical calibration: a requisite for evapotranspiration formulae based on daily or longer mean climate data. Budapest: International Commission on Irrigation and Drainage, 1977, 19p.

ROBINSON, J.M;. HUBBARD, K.G. Soil water assessment model for several crops in the High Plains. Agronnomy Journal, Madison, v.82,p.1141-1148, 1990.

ROSENBERG, N.J.; BLAD, B.L.; VERMA, S.B. Microclimate: the biological environment. 2.ed. New York: John Wiley \& Sons, 1983. 495p.

SANDERSON, Marie. The climates of Canada according to the new Thornthwaite climatic classification. Scientific Agriculture, Toronto, v.28, p.501-517, 1948.

SANDERSON, Marie. Three years of evapotranspiration at Toronto. Canadian Journal of Research, Toronto, v.28, p.482-492, 1950a.

SANDERSON, Marie. Some canadian development in agricultural climatology. Weather, Toronto, p.381-412, 1950b.
SEDIYAMA, A.D. Estudos de métodos para estimativa de evapotranspiração potencial em Viçosa. Viçosa, 1972. 43p. Tese (Magister Scientiae) - UFV.

SMITH, G.W. The determination of soil moisture under a permanent grass cover. Journal of Geophysical Research, Washington, v.64, p.477-483, 1959.

SMITH. M. Report on the expert consultation of proceedures for revision of FAO Guidelines for prediction of crops water requirements. Rome: FAO, 1991. 45p.

STANHILL, G. A comparison of methods of calculating potential evapotranspiration from climatic data. Israel Journal of Agricultural Research, Bet- Dagan, v.11, p.159$71,1961$.

STEINER, T.A.; HOUER, T.A.; SCHEIDER, A.D. Lysimetric evaluation of daily potential evapotranspiration models for grain sorghum. Agronomy Journal, Madison, v.83, p.240-247, 1991.

THORNTHWAITE, C.W.; WILM, H.G. Report of the Commite on evapotranspiration and transpiration, 1943-1944. Washington, D.C.: Transactions of the American Geophysical Union, 1944. p.686-693.

THORNTHWAITE, C.W. The moisture factor in climate. Transactions of the American Geographical Union, Washington, D.C., v.27, p.41-48, 1946.

THORNTHWAITE, C.W. An approach toward a rational classification of climate. Geographical Review, New York, v.38, n.1, p.55-94, 1948.

THORNTHWAITE, C.W.; HOLZMAN, B. Evaporation and transpiration. In: Climate and Man: Yearbook of Agriculture - 1941. Washington D.C : U.S. Department of Agriculture, 1941, p.545-550.

THORNTHWAITE, C.W.; MATHER, J.R. The water balance. Centerton, N.J.: Drexel Institute of Technology - Laboratory of Climatology, 1955. 104p. (Publications in Climatology, v. 8, n. 1)

THORNTHWAITE, C.W.; MATHER, J.R. Instructions and tables for computing potential evapotranspiration and water balance. Centerton: Drexel Institute of Technology Laboratory of Climatology, 1957. 311p.

UBALDI, P. Queda e salvação. São Vicente: Manismo, 1965, $414 \mathrm{p}$.

VILLA NOVA, N.A. Estimativa da evapotranspiração no Estado de São Paulo. Piracicaba, 1967, 66p. Tese (Doutorado) - ESALQ-USP.

VILLA NOVA, N.A.; REICHARD, K.; ORTOLANI, A.A. Principais métodos de estimativa e de medida da perda de água de superfícies naturais. Piracicaba: ESALQ -USP, $1968,57 \mathrm{p}$.

WILLMOTT, C.J.; ROWE, C.M.; MINTZ, Y. Climatology of the terrestrial seasonal water cycle. Journal of Climato$\log y$, v.5, p.589-606, 1985. 